\title{
Key Insights into What Makes Public Organizations Learn from Training Programs'
}

\section{Kristin Reichborn-Kjennerud ${ }^{2}$}

PhD, Oslo Metropolitan University, Work Research Institute, Oslo, Norway

\begin{abstract}
Public organizations often operate in rigid environments with standardized procedures that are not conducive to learning, yet it is crucial that they continuously improve at solving their societal tasks in a satisfactory way. There is a lack of knowledge about what factors are important for learning to occur in public organizations. Based on a questionnaire, this study looks at how different factors condition the way in which employees perceive standardized training programs in public organizations. The study demonstrates how a training program was perceived by two different professional groups, one being more accustomed to and accepting of standardized procedures than the other. The results show that the child welfare services had a more positive attitude toward the program than did the family counseling services. Employees working in an environment that is positive to employee feedback also perceived the program as more relevant, important and useful. Employees working in an environment that prioritized competence development perceived the program to be better organized and implemented and to be relevant to their work tasks. The article argues that these factors contribute positively to organizational learning and stresses the importance for leaders to develop an environment that is positive to employee feedback.
\end{abstract}

\section{KEYWORDS}

Organizational change / organizational learning / public organizations / training program

\section{Introduction}

$\mathrm{t}$ is crucial that public organizations continuously evolve and improve at solving their societal tasks in a satisfactory way, but there is a lack of knowledge about how public organizations learn (Betts \& Holden 2003; Jarvie 2018; Sitzman \& Weinhardt 2015; Smith \& Taylor 2000). This paper seeks to close this gap. Using a questionnaire, it looks at how different factors, including different professional cultures, condition the way in which employees perceive standardized training programs in public organizations.

Public organizations differ from private organizations in that they manage the taxpayers' money. They are thus at risk of potential criticism for mismanagement, inefficiency, ineffectiveness and corruption (Wæraas et al. 2011).

In addition to being accountable for the use of public money, public organizations are increasingly expected to continuously improve their organization in order to deliver value for money (Reichborn-Kjennerud 2013; Yeo 2007). Public organizations generally also face constitutional constraints and wider accountability expectations, and have multiple constituencies (LaPalombara 2003). To change and improve is therefore more of a challenge in a public organization.

\footnotetext{
${ }^{1}$ You can find this text and its DOI at https://tidsskrift.dk/njwls/index.

${ }^{2}$ Corresponding author: rekr@oslomet.no.
} 
This paper investigates how the training program was perceived by two different professional groups, one being more accustomed to and accepting of standardized procedures than the other. Perception of the program is used as a proxy because accepting and perceiving the program positively is crucial for motivation and for learning to occur (Revans 1980, p. 277; Senge 2006; Yeo 2007).

\section{Learning in public sector organizations: the research gap}

Creating an organization that is learning is challenging, particularly in the public sector. Public organizations operate under conditions that are actually counterproductive to learning (Jarvie 2018; Smith \& Taylor 2000). In their research, Smith and Taylor (2000) nevertheless could not establish that accountability pressures in the public organizations they studied impeded learning. However, Reichborn-Kjennerud et al.'s research shows that holding public organizations to account through performance audits will actually make public organizations implement measures and possibly improve their organizations (Althauser 2015; Reichborn-Kjennerud 2013, 2014; Reichborn-Kjennerud \& Johnsen 2018; Reichborn-Kjennerud \& Vabo 2017; Reichborn-Kjennerud \& Vrangbæk 2016, Sitzman \& Weinhardt 2015).

The literature on learning in public organizations is very sparse (Betts \& Holden 2003; Jarvie 2018; Smith \& Taylor 2000). Little attention has been paid to the topic of change in government agencies, and consequently the topic is not much discussed. Organizational change tends more to be a topic of interest in journals focusing on general management and organizational theory (Fernandez \& Rainey 2006). Given the importance of context, there is a need for greater clarity as to what actually constitutes learning in a public sector environment (Jarvie 2018).

The number of relevant contributions is sparse. From Lundkvist and Gustavsson's (2018) recent article, we see an example of a competence development program facing problems due to a restrictive learning culture in the workplace. The policies and prevailing internal organizational conditions contributed to decoupling talk from action. This happened even though the public organization had external support from a workplace development program. Betts and Holden's (2003) article underlines that organizational power patterns can stifle learning efforts in public organizations. They point to a lack of empirical examples of learning in public organizations and to the need for more knowledge on how to build learning capacity. Rebelo and Gomes (2003) investigated what influenced a learning culture in the workplace. The study demonstrated that a learning culture was positively correlated to flexible, organic structures (which cannot be said to characterize public hierarchies).

Based on a qualitative study, Kessler et al. (2001) discuss how standardized, competence-based training programs best can be implemented in a public health organization. This study found that implementation processes must be dynamic, not stagnant, and be continuously evaluated and adapted to reflect changing contexts. Total quality management (TQM) programs correlated positively, but certification correlated negatively to producing a learning culture in Rebelo's study (Rebelo \& Gomes 2003), but this finding was also mediated by size, the largest companies being less oriented to learning. Employee participation in decision-making positively influenced learning. Training programs did not seem to be sufficient to promote a learning culture. If the programs 
were not supported by their organizational environment, they proved to be inefficient (Reeves 1996).

Some research exists on how professions react to new public management systems and standardized procedures for continuous improvement (Nygaard \& Bramming 2008; van Bockel \& Noordegraaf 2006), indicating that successful quality programs can only be implemented by committed and involved staff. Whether the staff is involved will again depend on the degree of ownership and cooperation from staff members closest to the point of service delivery (Patel 1994). It is therefore important how standardized programs are implemented and how employees perceive them. The literature on how learning from standardized improvement programs occur, specifically taking account of differences in professional cultures, is sparse.

\section{Theory}

What we set out to understand in this study was what factors are important for employees in public organizations to learn from training programs. To understand this, we utilize the concepts of learning and motivation. Learning relates to actual change, or potential change, on different levels in the organization, and motivation relates to why and how employees change their behavior. Motivation precedes learning, learning being the natural consequence of employees' motivation to change their behavior.

Motivated employees are more conducive to learning than are employees who are not. Motivation therefore increases training effectiveness (Sahinidis \& Bouris 2008). Motivation, as the name suggests, is what moves us. It is the reason we do anything at all. The way in which employees perceive a training program will motivate them to use the new methods the training program teaches. The proxy we use for motivation in this study is therefore employees' perceptions of the training program.

Motivation influences learning. The actual learning will occur at different levels in an organization: individual, small group or organization/workplace. Organizational learning is seen as change, or potential change, in actions, structures, culture, policies or something else manifested in an organization/workplace beyond the individual or small group.

Change, or potential change and learning, in an organization, is contingent on a number of factors. Professional cultures within the organization and the values and skills employees acquired in their education constitute one such factor. A number of different professional cultures can simultaneously exist, shape the organizational culture and influence the propensity for change (Bloor 1994).

Another factor is the design of the program itself and the support that employees receive in implementing the program. If they receive the support, they need to master the new methods in the training program, they are more likely to have a more positive perception of it. Both the training program itself and the organizational system matter for their propensity to change (Mathieu et al. 1992; Sitzman \& Weinhardt 2015).

A third factor is the culture in the organizational unit in which the employees work. In an organizational unit with a learning culture, self-reflection will be easier (Enehaug 2014). Self-reflection and reflective experiences in communities of practice are what lead to transformation (Elkjær 2001). The employees' propensity to change will be higher in a workplace unit that cultivates a learning culture that is open to feedback from employees. 
Employees can have different motivations to learn and use new work methods. We can distinguish between intrinsic and extrinsic motivation and between instrumental and integrative motivation. Intrinsic motivation stems from an interest in the activity itself, which in our case means becoming a better helper. The extrinsically motivated employee is oriented toward avoiding punishment and gaining rewards from doing the activity. The instrumentally motivated employee is primarily interested in upgrading her skills. The integratively motivated employee is interested in training as a tool to do a better job with clients and colleagues in the workplace. For the intrinsically and integratively motivated person, her perception of the training program as a tool that will improve her ability to do a good job and help the clients is important. She will be open to expansive, or doubleloop, learning if new methods are helpful, and less willing to use them if they are perceived as not helpful. A learning culture will contribute positively because it will give these employees room for reflection around how new methods can be useful (Chang 2005).

According to Fuller and Unwin (2011), expansive learning, which is similar to the concept of second-order, or double-loop, learning, occurs in organizations that allow for 'substantial horizontal, cross-boundary activity, dialogue and problem-solving'. Both individuals and the organization itself need to change, and they need to engage in reflective experiences to allow for expansive learning (Elkjær 2001; Engestrøm 1987). The importance of leaders in cultivating this type of learning culture in organizations is well known (DuFour \& Marzano 2011).

\section{About the organization we studied}

The Norwegian Directorate for Children, Youth and Family Affairs (Bufdir) is a public body responsible for child welfare, youth, adoption, family counseling, equality, nondiscrimination and prevention of violence and abuse in family relations. Bufdir controls the Office for Children, Youth and Family Affairs (Bufetat 2017), which is the public agency responsible for child welfare and family counseling services in Norway. The agency caters to families and to children who have not been properly taken care of in their families, and its strategic goal is to provide high-quality services to its users, the core users being families and children in need of assistance. The agency faces strategic challenges. It must digitalize the service, improve the quality of its services, improve collaboration and participation, deal effectively with continuous change, improve security, ensure equal services to users and increase efficient delivery of services.

Bufetat has offices in five regions in Norway, and within each region Bufetat provides services within child welfare, youth welfare and family counseling. It is vital that the services provided are of sufficient quality and that the Norwegian population has access to more or less the same type of services regardless of where they live.

While the child welfare functions of Bufetat have been using standards and best practices, the family counseling function has been less used to standardization. Many family counseling units are run by the Church of Norway, but are fully financed by the state. They have traditionally had more leeway and are more accustomed to professional discretion in their work than are the child welfare services. They are not necessarily against routines as such, but may disagree with their design.

The two units differ considerably both in the way they work (the child welfare units being more used to standardized procedures) and in their background and traditions. 
This makes this organization a good case for this study. The two units embody two very different professional cultures and exemplify the different ways in which they perceive standardized training programs.

\section{About the training program}

The new training program implemented in the organization of study seeks to integrate learning from experienced employees with best practice elements from scientific knowledge. The program is a mixture of standardizing best practice from research and best practice from the organization itself. However, the organization is marked by professional divisions and organizational differences that may result in different responses to these kinds of programs.

The training program the organization introduced aims to solve strategic challenges. The purpose of implementing the program is to standardize and enhance competence in the organization with the aim of improving quality and results.

Development and implementation of the training program are organized into expert and facilitator groups. The first expert groups (spisskompetansemiliøer) in the competence development program were established in 2015 to support development of frontline workers' skills and qualifications in the child welfare and family counseling services. The expert groups were intended to promote best practice in the organization and provide professional guidance to the frontline workers. The program was presented as a 'knowledge pyramid', with expert groups at the top of the structure, regional counseling, training and knowledge facilitator groups in the middle, and the frontline workers or 'generalists' at the base.

The mandate for the expert groups was threefold: to develop a knowledge platform within the groups' line of service; to create professional guidelines based on this knowledge; and to implement these guidelines in the organization. The development of these knowledge platforms was supposed to combine research-based knowledge with the experience-based knowledge of the frontline workers. The base of the knowledge pyramid thus plays an important role in forming the expert advice. This differs from evidence-based practice in that the platform incorporates both employee experiences and user perspectives. The program had expert groups in the following areas:

Expert groups in the child welfare services:

- Training for foster parents, emergency shelters, safety in community homes, social work with youth in community homes, investigation and treatment of vulnerable parents with infants and small children, and youth rehabilitation.

Expert groups in the family counseling services:

- Violence in families, families with strong conflicts after split-ups, parents without custody of their own children and preventive measures for vulnerable families.

The purpose of the training program was to 'reduce undesirable variation in practice' in the state's child welfare and counseling services (Bufetat 2017) and to professionalize the 
services. Previous competence development programs did not have sufficient continuity and failed to utilize expertise that already existed. This new competence development program tries to resolve these problems.

Previously, a lot of resources were used on ad hoc skills upgrading [...] that was quickly forgotten. We were not able to incorporate them into an integrated structure. This is some of the background for the model. [...] We asked ourselves how we could take advantage of the fact that some employees are more skilled in some areas than others, and how this could benefit the service as a whole. (Leader)

The main organizing principle of the program has been to gather expert teams from within the organization. The tasks of the teams are to develop guidelines and procedures for the rest of the organization. In addition, facilitator groups assist in implementing these guidelines and procedures in other units within the organization.

The expert teams are part of the organization, embedded in ordinary units such as family counseling offices or youth homes. The teams should support the offices in the rest of the country through a hierarchical knowledge diffusion model. Each expert team is located in one of the five regions. In each of the other four regions, a facilitator unit has a 'counselling function' for that same expert area, and is responsible for implementing the competence model in each region. All organizational units in Bufetat may provide input to the expert groups to refine best practices in a continuous manner.

In 2018, 10 expert groups had been established within the Bufetat organization focusing on different themes. One example of a theme is 'violence in close relations', which is defined as an important field of inquiry in family counseling. Another example is 'techniques for preventing situations escalating' in youth homes. The program is designed to re-evaluate and update the guidelines every fifth year.

\section{Research design and hypotheses}

The mindset of individuals needs to change before changes can occur in organizational systems (Revans 1980, p. 277; Senge 2006; Yeo 2007). The employees' perceptions of the training program are therefore a crucial prerequisite for actual learning. In this study, we therefore asked the employees about how they perceived the training program in question

We operationalize the contextual/situational variables as: (1) 'learning culture in the workplace' measuring how open the organization is to employee feedback and suggestions; (2) 'the program and implementation of the program' measuring the effectiveness of the program in terms of how well the program involves, helps and informs the employees; and (3) 'professional culture' measuring the significance of professional culture in learning from standardized training programs.

Our three hypotheses are:

H1: The more the workplace culture promotes learning, the more positive the employees will be toward the training program.

$\mathrm{H} 2$ : The more support the employees receive from the training program, the more positive they will be toward it. 
H3: The more the employees' work tasks are traditionally based on discretion, the less likely they will be to accept the training program.

The training program in this study aims to enhance competence and quality. What is interesting to consider when investing in training programs is how successful they are in changing employees' perceptions and practices. In our study, we look specifically at how situational variables (learning culture, implementation of the program and professional culture) influence perceptions (see Figure 1).

Figure I Our model.

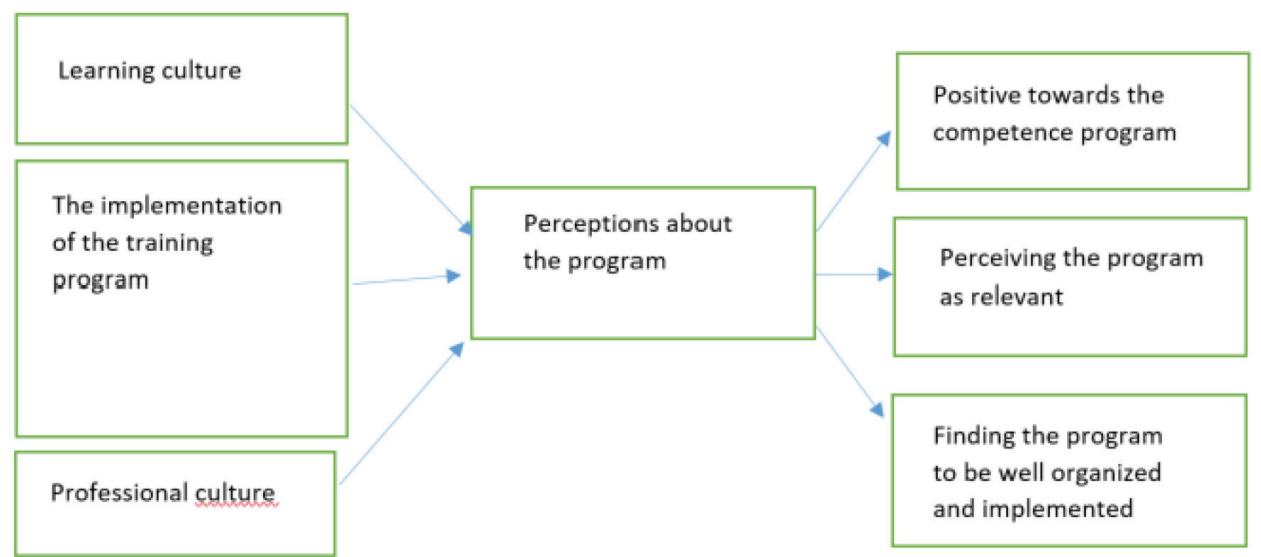

The model hypothesizes that aspects of organizational and professional culture as well as the program itself influence the employees' perceptions of the program, which in turn will influence the impact of the program.

Evidence suggests that a considerable part of an organization's investment in training fails to result in optimal training transfer. To improve job performance, the skills and behaviors learned and practiced during training have to be maintained over time and generalized across contexts (Holton \& Baldwin 2003; Scaduto et al. 2008). Organizational and professional cultures are important for this long-term effect.

The proxies we use in the analysis are question batteries that measure what a learning culture is, how much support the employees think they received from the program, how involved they are and their professional background and readiness for standardizing procedures.

\section{Methods}

In this project, we distributed a questionnaire to all employees in the organization. Questionnaires are typically used to profile a 'population' (Rowley 2014). The questionnaire was sent to all employees in the organization $(\mathrm{N}=6087)$ except for the administrative unit. Before the questionnaire was distributed, it was tested on employees at different levels and with different tasks in the organization. The questionnaire was then adjusted 
in line with the comments. We used an electronic survey program (Questback) to distribute the questionnaire and administer the responses. The questions are nominal categories or ordinal scales on a 5-point Likert scale. The nominal variables were converted into dichotomous variables in the analysis.

We received 2205 responses to the 6087 questionnaires distributed. The response rate for the questionnaire was $36 \%$. Many employees in the organization work parttime and rarely use e-mail at work. This, and the fact that the training program is not equally relevant for all employees and many may therefore not even be aware of the programs' existence, explain the relatively low response rate. There is reason to believe that those who responded had qualified opinions on the program.

The data were screened prior to analysis. This included data cleaning and treatment of outliers and missing data (Meyers et al. 2006). A thorough descriptive analysis was also conducted before running the regression analyses.

Before and after distributing the questionnaire, we interviewed a broad range of people with dedicated responsibilities for the training program. The interviews conducted before the questionnaire was distributed formed the basis for developing the questionnaire. We interviewed people with different roles and responsibilities in the organization to understand the training program and how it was organized, and designed the question batteries based on that information. We then tested the questions on selected informants and adjusted them before distributing the questionnaire to the whole organization.

\section{Analysis of the data}

In this article, the qualitative data are used in the description of the case and as a backdrop for our interpretation of the results from the quantitative analyses. For the quantitative analyses, we first show the descriptive analyses. The questions from the questionnaire batteries were converted into indexes through addition, that is, the values for the questions in the indexes were added up. The indexes were used as dependent variables in three regression analyses. The indexes were tested for internal consistency with Cronbach's alfa. Cronbach's alfa measures the strength of the statistical correlation between the questions along the same underlying dimension. A value of more than 0.7 is considered sufficient for a question to be included in an index measuring the same dimension. Only questions of more than 0.7 were included in our indexes.

For the analyses, we selected the 1294 respondents who had responded that the work of the expert and facilitator groups in the training program was relevant to their job in the organization. The analysis revealed 12 cases with $33 \%$ or more missing values. We deleted these from the dataset. Our final $\mathrm{N}$ was therefore 1282.

\section{Indexes}

The questions that make up part of the indexes (the dependent variables in the regression analyses) are presented in the charts below.

Figure 2 illustrates whether or not the employees are positive toward the training program in general. The questions forming part of the index are (1) whether employees 
think that the program enhances the competence in the organization, (2) whether they consider it an improvement compared to previous practice and systems, and (3) whether they consider it the right measure to implement to improve the quality of operations.

Figure 2 Importance and usefulness of the training program. Percent. $\mathrm{N}=$ | | 39- | | 44.

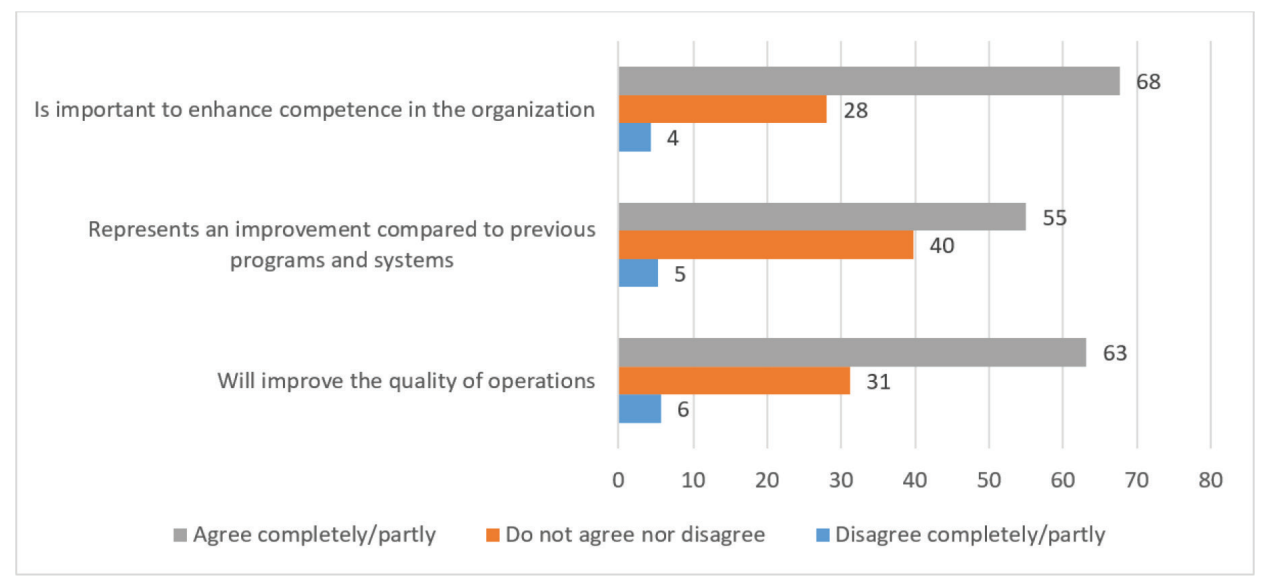

Figure 2 demonstrates that two out of three employees (68\%) consider that the training program enhances competence in the organization. More than half of the employees consider the training program to represent an improvement compared to previous practice and systems. Between $30 \%$ and $40 \%$ neither agree or disagree with the questions. More than $60 \%$ of the employees consider the training program to qualitatively improve the organization.

Figure 3 illustrates whether or not the employees consider the training program to be relevant to their work. The questions forming part of the index are (1) whether the training program gives them a framework and provides good routines, (2) whether it gives them confidence and a sense of security, (3) whether it is a useful tool in dealing with users and clients, and (4) whether it is directly relevant to their work tasks $(65 \%)$.

As the figure demonstrates, $50 \%$ or more of the employees think that the competence development program is relevant to them for providing good routines, useful tools, confidence and a sense of security. Sixty-six percent consider the program to be directly relevant to their work tasks.

Figure 4 illustrates whether or not employees consider the training program to be well organized and implemented. The questions forming part of the index are (1) whether the agency takes sufficient responsibility for the facilitator groups, (2) whether the agency takes sufficient responsibility for the expert groups, (3) whether the facilitators' tasks are clearly defined, (4) whether the expert groups' tasks are clearly defined, (5) whether several parallel initiatives create confusion and coordination problems, and (6) whether the work areas included in the program are the most important ones.

Few respondents have clear opinions about the organization and implementation of the training program. Between $45 \%$ and $70 \%$ respond that they neither agree nor disagree 
Figure 3 Relevance of the training program. Percent. $N=|| 72-|| 86$.

Represents a framework and provides good routines for dealing with users and clients

Gives me useful tools in dealing with our users and clients

Gives me confidense and a sense of security

Directly relevant for my worktasks

$$
0
$$

agree completely/partly

Do not agree nor disagree

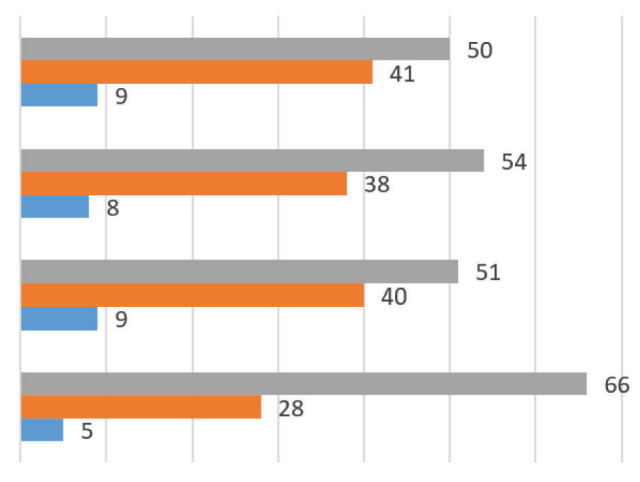

$20 \quad 30 \quad 40 \quad 50 \quad 60$

Figure 4 Organization and implementation of the training program. Percent. $N=\mid$ | 34- | | 49.

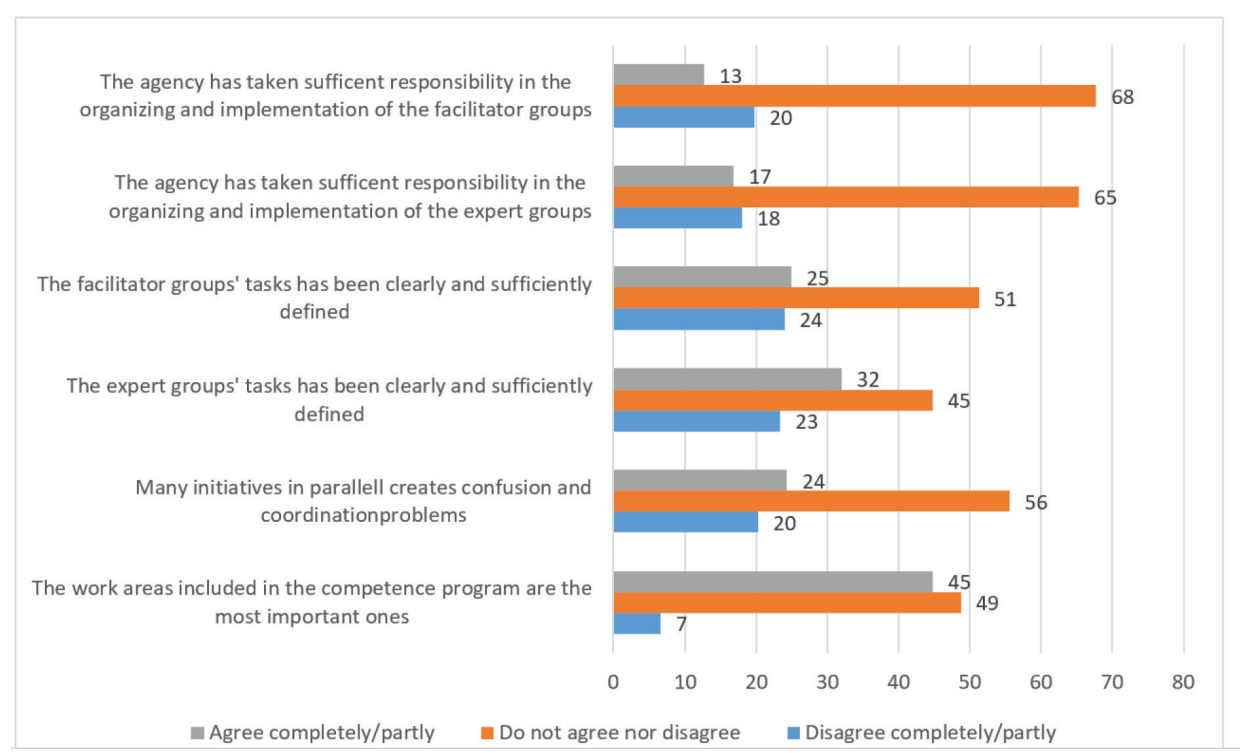

with the questions. Many expert groups are still in the phase of developing knowledge and are not yet deployed it in the organization, which may explain these high numbers.

In the regression analyses, we used these three indexes as dependent variables. We performed three ordinary least squares regression analyses with the three different indexes as their dependent variable. 
The indexes measure

(1) The employees' perceptions of the training programs' importance and usefulness

(2) How relevant the employees consider the training program to be to their work

(3) How well the employees consider the training program was organized and implemented

The questions in the questionnaire are coded from 1 to 5 where 1 denotes the lowest value and 5 denotes the highest, and thus most positive, value. The higher the value of the index, the more positive the employees perceive the training program.

\section{Independent variables}

Independent variables as proxies for measuring organizational culture are questions regarding both how employees perceive they are listened to in their workplace and how they perceive competence development and evaluation to be prioritized in their workplace. Independent variables as proxies for implementation of the program are employees' perceptions of the training program. The independent variables on professional culture are whether the employees work in the family counseling units or in the child welfare units.

The control variables in the regression models are gender, age, manager/subordinate, educational level and work experience in the organization. Age has been shown to have an important independent influence on training effectiveness, as have situational variables such as manager and peer support (Colquitt et al. 2000). In the model, we measure involvement in and support from the training program. It is therefore important to control for the employees' positions in the organization. Leaders naturally tend to be more involved. The same applies for educational level, work experience and time used in expert or facilitator groups. See Table 2 for an overview of the independent variables.

\section{Regression analyses}

In the regression analyses, we look more closely at what influences the employees' perceptions of the training program.

The first regression analysis in Table 1 demonstrates that employees in the child welfare unit are more positive to the training program than the employees in the family counseling units. Leaders are also more positive than employees without leadership responsibilities. The first regression analysis shows that employees who had to perform tasks, which in their opinion should have been done differently are less positive toward the training program than others. If the culture in the workplace encourages the employees to suggest new and improved ways of working, they are also more positive to the program. In addition, the first regression analysis demonstrates that the better the employees know the training program, have had more contact with the expert and facilitator groups and have local trainers in the workplace, the more positive they are.

The second regression analysis demonstrates that employees who had to perform tasks, which in their opinion should have been done differently consider the training program to be less relevant to their work tasks than do other employees. Employees with a good learning culture in their workplace see the training program as more relevant 


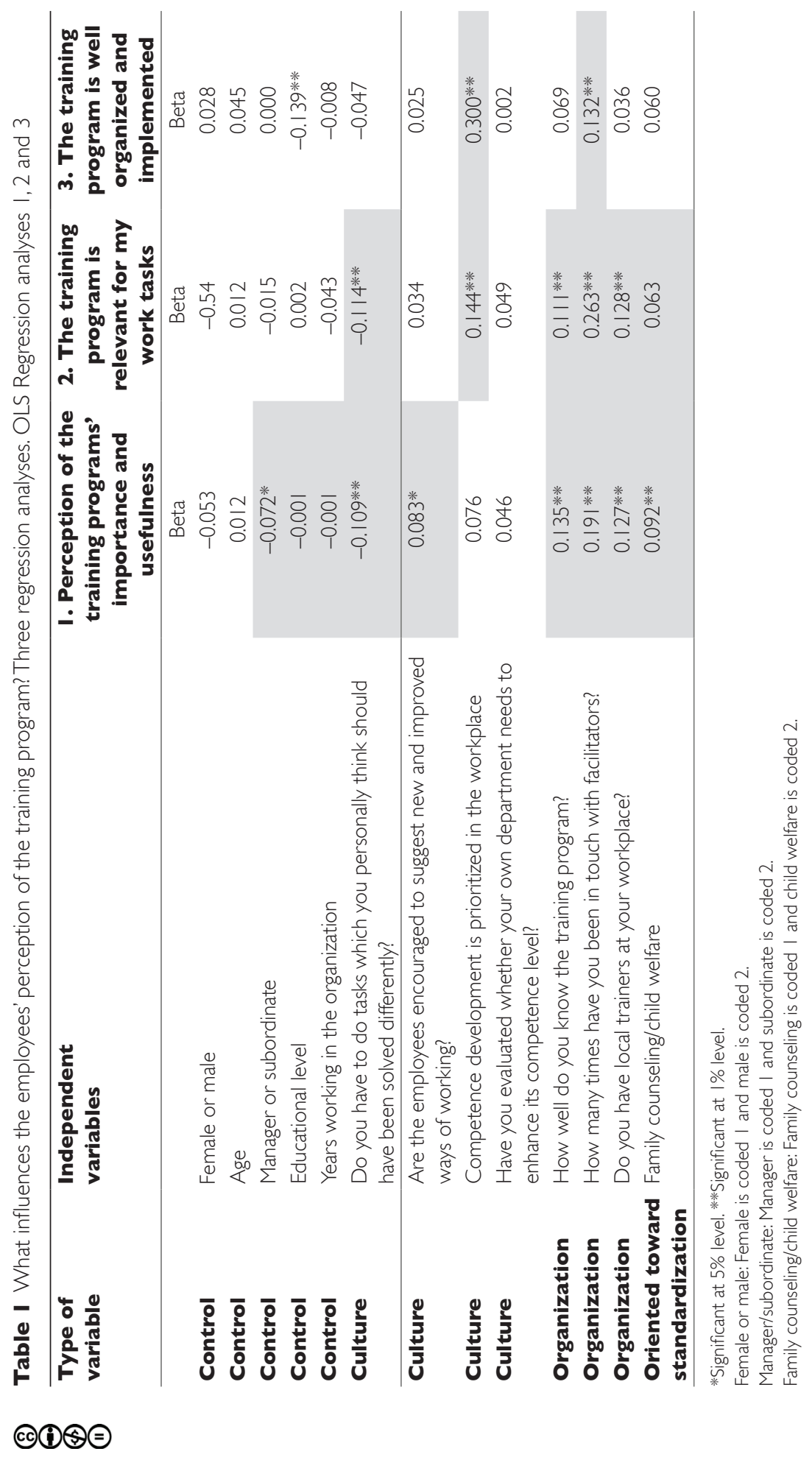


Notes for the regression analyses:

\begin{tabular}{lccc}
\hline & $\begin{array}{c}\text { Positive to the } \\
\text { competence } \\
\text { development } \\
\text { program in general }\end{array}$ & $\begin{array}{c}\text { The competence } \\
\text { development model } \\
\text { is relevant }\end{array}$ & $\begin{array}{c}\text { The competence } \\
\text { development model } \\
\text { is well organized }\end{array}$ \\
\hline $\mathrm{N}$ & 724 & 736 & 718 \\
Adjuster $\mathrm{R}^{2}$ & 0.244 & 0.265 & 0.196 \\
F statistics & 17.592 & 21.405 & 13.180 \\
Significance of $\mathrm{F}$ & 0.000 & 0.000 & 0.000 \\
\hline
\end{tabular}

for their work tasks than do other employees. Learning culture is operationalized here through questions about time for workers to learn during working hours, getting support when they want to learn new things, and having sufficient training and time to acquire new skills. The better the employees know the training program, have had more contact with the expert and facilitator groups and have local facilitator contact persons in the workplace, the more relevant they consider the training program to be.

Few respondents have opinions about the organization and implementation of the training program (see Figure 3). The third regression analysis still shows that the higher the employees' educational level, the more skeptical they are to how the training program has been organized and implemented in the organization. The third regression analysis also demonstrates that employees with a good learning culture in the workplace think that the training program has been organized and implemented better than do other employees. If they have been in contact with facilitators often, they are also significantly more positive toward the organization and implementation of the program.

\section{Discussion}

Our research confirms that having a learning culture, being open to employees' feedback and prioritizing competence development in the workplace contribute positively to employees' perceptions of the training program. Reflective experiences in communities of practice is what leads to transformation, according to Elkjær (2001). When employees perceive their workplace as reflective, this is likely to contribute to expansive learning. The first two regression analyses measuring employees' perceptions of the programs' importance, usefulness and relevance varied significantly with independent variables for the learning culture dimension. This means that the more the workplace allows for selfreflection, participation and suggestions from employees, the more positive employees are toward the program (Enehaug 2014).

As demonstrated in previous, predominantly qualitative, research (Reeves 1996; Zumrah 2015), a learning culture in the workplace contributes to better training transfer. This finding is confirmed in our large $\mathrm{N}$ study. There is a general tendency for employees to be more positive toward the training program if their organizational unit prioritizes competence development in the workplace. The more competence development was prioritized in the employees' workplace in general, the more relevant they 
found the training program to be. This may indicate that in organizational units with a learning culture (double-loop), employees will be less skeptical to new practices and more positive to trying out new ways of working (Enehaug 2014).

Participation is an important element in securing the legitimacy of organizational changes in the workplace that contribute positively to employees' opinions about new standards (Reeves 1996). Resistance can be a sign that that participation and involvement of employees have been too weak in the development of the standards. Resistance can therefore be interpreted as a healthy reaction to single-loop solutions handling complex problems that should have been dealt with more reflexively. Resistance can, nevertheless, also be a sign that employees resist the new training because they feel uncomfortable doing things in a new way (Enehaug 2014). The reason for employee resistance will depend on the employees' motivation, whether they have an intrinsic or extrinsic motivation or whether they have an instrumental or integrative motivation (Chang 2005). The intrinsically and integratively motivated person will be open to expansive, or double-loop, learning if new methods are helpful, and will resist if they are perceived as not helpful. A learning culture and openness to employee feedback can positively influence their opinions about the new standards.

Moreover, our research demonstrates that a professional culture that is accepting of standardizing procedures is more positive toward training programs for implementing standards for best practices (Bloor 1994). The first regression analysis indicates that employees in the child welfare services, more so than in the family counseling services, consider the training program to be important and useful. The employees in the child welfare services are more used to, and positive toward, standardizing procedures because they can help them handle difficult situations, whereas the employees in the family counseling services, who are less accustomed to procedures as such, are less positive. This is a contribution to the literature because the importance of professional culture for workplace learning in public organizations has not previously been addressed. One interpretation could be that employees in the family counseling unit feel less comfortable with programs that aim to standardize and exert more control over work tasks.

The most important factor, nevertheless, proved to be the ability of the program itself to inform, support and help employees in their everyday work situations. The third regression analysis, measuring how the training program was organized and implemented, was positively and significantly correlated with the independent variable measuring how often employees were in touch with training facilitators (Patel 1994). The independent variables measuring how closely employees were in contact with the program and with facilitators were also clearly and significantly correlated with employees' perceptions of the program as important, useful and relevant to their work tasks. Support and involvement from the program itself thus increases employees' positive perceptions of the training program. This may increase the long-term effectiveness of the program, and indicates that sufficient follow-up of employees is a key factor for successful learning in the workplace. Both this study and previous research seem to suggest that support and involvement from staff is key for employees in public organizations to learn from trainings programs. This corroborates the second hypothesis that the more support the employees receive from the training program, the more positive they will be toward it. Successful training programs depend on involved and committed staff (Patel 1994). 
The literature finds that programs that are flexible to the situation, responsive to employee suggestions, uncontroversial and accepted contribute more to learning (Holton \& Baldwin 2003; Kessler et al. 2001; Lundkvist \& Gustavsson 2018). Our study demonstrates that it is equally important that the actual program informs, supports and helps employees to understand (Patel 1994). This increases their acceptance of new knowledge provided through the program. There need not necessarily be conflict between standardizing procedures and learning, as indicated by Rebelo and Gomez (2003), as long as the program supports the employees sufficiently in the implementation of new routines.

If employees have been in personal contact with the expert and facilitator groups, they are much more positive and find the program more relevant to their work. When they have local trainers in the workplace, they also find the training program more relevant and are generally more positive. It thus seems important for the success of such programs that they do not turn out to be merely paper exercises, but that the measures are seen and felt by the employees in the organization. This indicates that the more practical implications employees see from the training program, the more relevant they will find it.

It is not unusual for leaders to be more positive to the implementation of new topdown initiatives in organizations. This was also the case in our study. Leaders are often more loyal to the organization and to top-down measures. The fact that leaders are more positive can be due to their role as knowledge agents in the bureaucracy. Through this role, they will know the program better, be more involved and thus more satisfied with it. Their involvement is also important because leaders have a substantial impact on the culture, systems and on the allocation of resources to follow up the training programs in organizations (DuFour \& Marzano). They are also key to ensuring a learning culture in their work unit.

These findings indicate that organizational culture (more or less oriented to learning) and the way in which new practices are implemented in the organization significantly increase the usefulness, importance and relevance of the program in the eyes of the employees. Researchers on training effectiveness should therefore broaden their scope to dig more deeply into how programs could best be organized and implemented taking into account differences in professional cultures and work tasks. Future research should focus on how to stimulate a learning culture in organizations because these factors seem to strongly impact the success of training programs. Leaders should also secure sufficient support in the implementation of new practices.

This study demonstrates that perceptions of the training programs' importance and usefulness were strongly influenced by the employees' professional backgrounds. It confirms that the more the employees' work tasks were traditionally based on discretion (as in the case of the family counseling services), the less accepting they were of standardizing procedures (Bloor 1994). In the development of training programs, it may therefore be important to consider and adapt them to the employees' professional backgrounds and culture to enable new knowledge to be effectively adopted in the organization

\section{Conclusion}

Initially, in this article, we asked how employees from two different professional cultures perceived a standardized training program in a public organization. The objective of this 
study was the introduction of a training program in a public organization. Our variables measured the learning culture, the implementation of the training program and the professional culture. We hypothesized that in organizations with a learning culture, employees would be more positive toward the training program. We also hypothesized that the more support the employees received from the training program, the more positive they would be toward it. Finally, we hypothesized that the more the work of employees with different professional backgrounds was based on discretion, the less likely they would be to accept a training program based on standardizing procedures.

The findings demonstrate how important it is that, for training programs to function optimally, leaders work to develop their organization and departments to become more learning-oriented. The study also confirms the importance of being present for employees and to support them in the implementation of the training program. The study shows that professional cultures matter for how useful employees perceive standardizing training programs to be, and that routines and standardized procedures need not be contradictory to learning. However, they need to be reflective routines and practices in order to be beneficial. It is therefore key that management supports a learning culture and follow-up of the training program.

A limitation of this study is that it does not document how employees actually learn from the training program in question, but rather how they perceive it. At the same time, employee perceptions of training programs are closely linked to their motivation for learning from the program. One essential element for training programs to be effective is that employees are positive toward them and consider them to be legitimate and effective.

The practical implication of the study is the importance for leaders to stimulate a learning culture in their departments. To support, follow up and be present for employees during training is also key in getting the most out of training programs. There may also be reasons to develop and implement training programs differently depending on the professionals' background and educational level.

\section{References}

Althauser, K. (2015). Job-embedded professional development: Its impact on teacher selfefficacy and student performance, Teacher Development 19(2): 210-225. doi: https://doi. org/10.1080/13664530.2015.1011346.

Betts, J., \& Holden, R. (2003). Organisational learning in a public sector organisation: A case study in muddled thinking, Journal of Workplace Learning 15(6): 345-348. doi: https:// doi.org/10.1108/13665620310488575.

Bloor, G., \& Dawson, P. (1994). Understanding professional culture in organizational context, Organization Studies 15(2): 275-295.

Bufetat. (2017). Spisskompetansemiliøene i Bufetat - modell, roller og ansvar. Unpublished internal document, Barne-, ungdoms-, og familieetaten.

Chang, M. M. (2005). Applying self-regulated learning strategies in a web-based instructionan investigation of motivation perception, Computer Assisted Language Learning 18(3): 217-230.

Colquitt, J. A., LePine, J. A., \& Noe, R. A. (2000). Toward an integrative theory of training motivation: A meta-analytic path analysis of 20 years of research, Journal of Applied Psychology 85(5): 678-707. doi: https://doi.org/10.1037/0021-9010.85.5.678.

\section{(1) $\odot \ominus$}


DuFour, R., \& Marzano, R. J. (2011). Leaders of learning: How district, school, and classroom leaders improve student achievement, Bloomington Indiana: Solution Tree Press.

Elkjær, B. (2001). The learning organization: an undelivered promise, Management Learning 32(4): 437-452.

Enehaug, H. (2014). Læring i omstillingenes tid: Et teoretisk innspill om arbeidsmiljø og organisasjonslæring [Teaching in times of organizational change: A theoretical contribution on working environment and organizational learning], Tidsskrift for Arbejdsliv 16(4): 69-84. doi: https://doi.org/10.7146/tfa.v16i4.108978.

Engeström, Y. (2015). Learning by expanding, New York: Cambridge University Press.

Fernandez, S., \& Rainey, H. G. (2006). Managing successful organizational change in the public sector, Public Administration Review 66(2): 168-176. doi: https://doi.org/10.1111/ j.1540-6210.2006.00570.x.

Fuller, A., \& Unwin, L. (2011). Workplace learning and the organization. In M. Malloch, L. Cairns, K. Evans \& B. N. O'Connor (Eds.), The SAGE Handbook of Workplace Learning (pp. 46-59), London: Sage.

Holton, E. F., \& Baldwin, T. T. (2003). Improving learning transfer in organizations, San Francisco: Jossey-Bass.

Jarvie, W., \& Stewart, J. (2018). Conceptualizing learning in the public sector: The importance of context, International Journal of Public Sector Management 31(1): 14-30. doi: https://doi.org/10.1108/ijpsm-08-2016-0137.

Kessler, S. A., Horton, K. D., Gottlieb, N. H., \& Atwood, R. (2012). Workplace learning for the public good: Implementation of a standardized, competency-based curriculum in Texas WIC, Journal of Workplace Learning 24(4): 270-285. doi: https://doi. org/10.1108/13665621211223388.

Lundkvist, A. H., \& Gustavsson, M. (2018). Learning conditions for continuous improvement in a public service organization, Journal of Workplace Learning 30(8): 578-591. doi: https://doi.org/10.1108/JWL-03-2018-0049.

LaPalombara, J. (2003). Power and politics in organization: Public and private sector comparisons. In M. Dierkes, A. B. Antel, J. Child \& I. Nonaka (Eds.), Handbook of Organizational Learning and Knowledge (pp. 557-581), Oxford: Oxford University Press.

Mathieu, J. E., Martineau, J. W., \& Tannenbaum, S. I. (1993). Individual and situational influences on the development of self-efficacy: Implications for training effectiveness, Personnel Psychology 46(1): 125-147. doi: https://doi.org/10.1111/j.1744-6570.1993.tb00870.x.

Meyers, L. S., Gamst, G., \& Guarino, A. J. (2006). Applied multivariate research: Design and interpretation. Thousand Oaks, CA: Sage.

Nygaard, C., \& Bramming, P. (2008). Learning-centred public management education, International Journal of Public Sector Management 21(4): 400-416. doi: https://doi. org $/ 10.1108 / 09513550810880269$.

Patel, A. (1994). Quality assurance (BS 5750) in social services departments, International Journal of Public Sector Management 7(2): 26-32. doi: https://doi.org/10.1108/09526 $\underline{869410055802 .}$.

Rebelo, T. M., \& Gomes, A. D. (2011). Conditioning factors of an organizational learning culture, Journal of Workplace Learning 23(3): 173-194. doi: https://doi.org/10.1108/ 13665621111117215.

Reichborn-Kjennerud, K. (2013). Political accountability and performance audit: The case of the auditor general in Norway, Public Administration 91(3): 680-695. doi: https://doi. org/10.1111/padm.12025.

Reichborn-Kjennerud, K. (2014). Performance audit and the importance of the public debate, Evaluation 20(3): 368-385. doi: https://doi.org/10.1177/1356389014539869.

Reichborn-Kjennerud, K., \& Johnsen, Å. (2018). Performance audits and supreme audit institutions' impact on public administration: The case of the office of the auditor general 
in Norway, Administration \& Society 50(10): 1422-1446. doi: https://doi.org/10.1177/ 0095399715623315.

Reichborn-Kjennerud, K., \& Vabo, S. I. (2017). Performance audit as a contributor to change and improvement in public administration, Evaluation 23(1): 6-23. doi: https://doi. org $/ 10.1177 / 1356389016683871$.

Reichborn-Kjennerud, K., \& Vrangbæk, K. (2016). Hvordan kan forvaltningsrevisjon bidra til organisasjonslæring?: En komparativ studie av Norges og Danmarks riksrevisjoner innenfor arbeids-og helsefeltet [How does performance audit contribute to organizational learning?: A comparative study of the Norwegian and Danish Supreme Audit Institutions in the work and health sectors]. Nordiske organisasjonsstudier.

Reeves, T. (1996). Rogue learning on the company reservation, The Learning Organization 3(2): 20-29. doi: https://doi.org/10.1108/09696479610113774.

Revans, R. W. (1980). Action learning: New techniques for management, London: Blond and Briggs.

Rowley, J. (2014). Designing and using research questionnaires, Management Research Review 37(3): 308-330. doi: https://doi.org/10.1108/MRR-02-2013-0027.

Sahinidis, A. G., \& Bouris, J. (2008). Employee perceived training effectiveness relationship to employee attitudes, Journal of European Industrial Training 32(1): 63-76. doi: https:// doi.org/10.1108/03090590810846575.

Scaduto, A., Lindsay, D., \& Chiaburu, D. S. (2008). Leader influences on training effectiveness: Motivation and outcome expectation processes, International Journal of Training and Development 12(3): 158-170. doi: https://doi.org/10.1111/j.1468-2419.2008.00303.x.

Senge, P. M. (2006). The fifth discipline: The art and practice of the learning organization, London: Random House Business.

Smith, K. D., \& Taylor, W. G. (2000). The learning organisation ideal in civil service organisations: Deriving a measure, The Learning Organization 7(4): 194-206. doi: https://doi. org/10.1108/09696470010342270.

Sitzmann, T., \& Weinhardt, J. M. (2018). Training engagement theory: A multilevel perspective on the effectiveness of work-related training, Journal of Management 44(2): 732756. doi: https://doi.org/10.1177/0149206315574596.

van Bockel, J., \& Noordegraaf, M. (2006). Identifying identities: Performance-driven, but professional public managers, International Journal of Public Sector Management 19(6): 585-597. doi: https://doi.org/10.1108/09513550610685998.

Wæraas, A., Byrkjeflot, H., \& Angell, S. I. (Eds.). (2011). Substans og framtreden: Omdømmehåndtering $i$ offentlig sektor, Oslo: Universitetsforlaget.

Yeo, R. K. (2007). Organizational learning in representative Singapore public organizations, International Journal of Public Sector Management 20(5): 345-365. doi: https://doi. org/10.1108/09513550710772486.

Zumrah, A. R. (2015). How to enhance the impact of training on service quality? Journal of Workplace Learning 27(7): 514-529. doi: https://doi.org/10.1108/JWL-06-2014-0048. 